\title{
Exploration of Ideological and Political Education in Public Health Emergency
}

\author{
LiChanghong ${ }^{1, a}$ \\ ${ }^{1}$ Marxist institute, ZaoZhuang University, ZaoZhuang, ShanDong, China \\ a173386601@qq.com
}

\section{ABSTRACT}

The successful "Chinese practice"against the epidemic situation can not be separated from the guidance of ideological and Political Education. Further exploration of the issues related to ideological and political education in public health emergencies will help us to accumulate experience and improve our ability to deal with similar incidents again.

Keywords: Public Health Emergency, Ideological and political education, Explore

\section{突发公共卫生事件中思想政治教育的探索}

李长虹 ${ }^{1, a}$

\footnotetext{
1 本庄学院马克思主义学院, 苯庄, 山东, 中国

${ }^{a} 173386601 @ q q . c o m$
}

\section{摘要}

抗击疫情成功的 “中国实践” 离不开思想政治教育的引导，同时它也给全国人民上了一次生动的思想政治教育 课。进一步探索在突发公共卫生事件中思想政治教育的相关问题,有助于再次应对类似事件积累经验提升能力。

关键词：突发公共卫生事件＼cjkstart思想政治教育＼cjkstart探索

\section{1. 前言}

全国上下抗击疫情成功的 “中国实践” 离不开思 想政治教育的引导，同时它也给全国人民上了一次生 动的思想政治教育课。

对全员进行思想政治教育既是做好疫情防控工 作的客观需要, 也有助于凝聚全民族力量继续奔赴共 同理想。此时, 进一步探索在突发公共卫生事件中思 想政治教育的相关问题, 有助于再次应对类似事件积 累经验提升能力。

\section{2. 思想政治教育内容的拓展探索}

新冠疫情使我们对原本熟悉的世界变得突然感觉 无法掌控, 给人们的正常生活带来了很大的不便, 在 生理和心理上都会对人们产生很大的影响。所以思想 政治教育的内容要不断丰富, 把思想政治教育与危机
教育、生命健康教育、安全教育、心理健康教育和应 急教育等内容相结合相渗透, 使之能够适应丰富多变 的现实生活成为系统的思想政治教育体系 ${ }^{[1]}$ 。

\section{1. 融入并重视危机教育}

中华民族是在不断地与各种危机的抗争中逐渐 成长起来的。危机也给我们的思想政治教育敲响了警 钟。在思想政治教育中融入并重视危机教育有利于受 教育者客观清晰地看待事物事件, 提升自己的认知能 力和科学应对的能力, 与党和国家保持一致。

在危机来临之前培养公民的临危不乱的品质, 宣 传科学防护求生的知识和技巧, 可以最大限度地保护 公民的生命安全和健康。

在危机面前, 人们难免会恐惧和惊慌, 可能会做 出与社会整体要求不一致的一些行为和举动。在思想 政治教育过程中加强危机教育, 提升公民对危机的防 
范意识和关注度，让公民在思想上对危机有较为客观 清醒的认识，不听信不传播并能保持镇定。

通过思想政治教育让公民充分认识自己的责任 担当，使公民在危机中能够及时有力地积极配合政府 的行政、政治动员。在此次抗击新冠疫情期间，公民 展现了较好的参与能力, 积极响应配合政府的防控部 署与号召, 形成了 “全民参与、群防群控” 的防控格 局, 为我国取得抗疫的阶段性成果提供了重要的保障、 积累了丰富的经验。

\section{2. 融入并重视生命健康教育 ${ }^{[2]}$}

党和国家对群众利益的重视、对人民生命的珍视。 民众充分感受到党和国家的温暖, 感悟到生命的价值, 全社会形成重视生命健康的共识, 有利于凝心聚力共 克疫情。

思想政治教育中生命健康教育的渗透, 更有利于 公民对生命健康系统的认识和理性的认知, 进而珍惜 生命、热爱生命, 保障生命的健康, 创造更大的自我 价值和社会价值 ${ }^{[3]}$ 。

\section{3. 安全教育嵌入思想政治教育}

树立并强化公民在安全教育中的主体地位, 引导、 鼓励支持公民开展自我教育, 充分发挥思想政治教育 工作者的重要作用, 与公安干警、安全保卫干部及社 区干部相互配合形成合力, 把安全教育融入到公民生 活、学习、工作和社会服务的各个方面。

新冠疫情在全世界蔓延, 中国政府实事求是及时 有效公布疫情信息, 全社会形成共识全员参与积极有 效应对。然而, 个别国家却不顾实情有意抹黑、甩锅 中国, 有意制造谣言企图瓦解我国民众抗击疫情的决 心和信心, 给我们的抗疫行动带来了不安全因素。所 以在处理突发公共危机中, 要在思想政治教育中关注 思想安全, 通过对民众的思想和信念的培植, 培养共 同的社会认同感并提供行动指导, 提升公众对社会价 值的认知与觉悟水平, 避免被反华势力渗透和洗脑。

\section{4. 融入心理健康教育 ${ }^{[4]}$}

此次新冠疫情对于大家来说是前所未有的一次 危机, 疫情的快速蔓延不同程度地给人们带来焦虑和 恐慌, 让人无所适从。公民的心理健康素质影响着其 认知能力与价值观取向, 影响着在此基础上形成的个 性化的判断体系。

思想政治教育中, 使受教育者合理的心理需求得 到充分满足，从而走进其内心世界帮助其放松心态、 调整状态 ${ }^{[5]}$, 正确认识自己、处理与周围人和事的关 系。

\section{5. 融入并重视应急教育}

此次新冠疫情让人猝不及防。党和政府组织科学 家和科研机构在充分研究的基础上, 向公众发布科学 防治的权威观点和专业意见建议。民众积极响应配合 政府的防控部署与号召实施群防群控, 为控制疫情战 胜疫情起到了积极的作用, 为以后开展应急工作提供 借鉴。

这也为我们开展常态化应急教育敲响了警钟。思 想政治教育承载着通过转变思想和价值认同的方式, 使民众对国家具有高度的认同感，对社会具有充分的 认同度等重要功能。在平时的思想政治教育中渗透常 规的应急教育，会使民众更好地认同政府的号召和举 措, 树立安全防范意识并保持清醒的头脑冷静地面对 灾难，用有力的应急手段强化求生技能，增强民众应 急救援能力。

总之，思想政治教育应该适应新时代的特点，根 据需要不断丰富其内容, 逐渐构筑起思想政治教育体 系。

\section{3. 拓展思想政治教育的功能}

在突发公共卫生事件中，思想政治教育的政治与社 会功能为凝聚全社会力量化解矛盾共克疫情发挥了 重要的作用。

\section{1. 充分发挥思想政治教育的认识功能}

此次公共卫生事件中，人们积极响应配合政府的 防控部署与号召, 投入到全民总动员的群防群控、科 学防控的洪流之中。思想政治教育有利于人们激发起 自己的责任感, 指导人们以科学的态度认识并辩证分 析事物和事件，以便选择合情合理合法可行的行为方 案。

\section{2. 充分发挥思想政治教育的传承功能 ${ }^{[7]}$}

此次新冠疫情防控的紧要关头, 党和国家号召民众 传承我国优秀民族传统，全国一盘棋。思想政治教育 通过对我国优秀民族精神和文化精髓的传承，人们团 结在共同认同的价值理念周围对科学防控形成全社 会的共识。这为我国迅速切断传染源、控制传染面, 为疫情防控取得阶段性成果起到了重要的保障作用。

\section{3. 充分发挥思想政治教育的叙事功能 ${ }^{[8]}$}

习近平同志特别重视讲好故事、讲好中国故事。 所以应当充分发挥思想政治教育的叙事功能，使人们 做出相应的心理调节和行为调整。

在疫情防控中涌现出了各行各业、各个年龄段为保 障人民生命安全和身体健康抗疫奔波的感人故事。在 思想政治教育中带着感情讲故事, 才能够更好地厚植 人们的爱国主义情怀，使人们把爱国情、强国志、报 
国行自觉融入当前群防群控科学防控的抗疫实践之 中 $^{[9]}$ 。

\section{4. 充分发挥思想政治教育的财富创造功能}

思想政治教育指导人们的有选择地取舍，激发人 们潜在的正能量的力量, 为社会提供精神财富。疫情 防控期间, 无论 30 后到 00 后的医务工作者还是其他 各行各业的广大民众, 都涌现出很多与病魔相斗争的 感人事迹, 孕育出 “抗疫精神”, 成为新时代中国人 民和中华民族的精神财富。

另一方面, 思想政治教育帮助劳动者正确认识自我 价值和社会价值, 积极高效投入到物质生产中, 为社 会创造更多的物质财富。

建设者们以短短 10 天左右时间先后建成 “火神山” “雷神山” 两座可容纳 1000 多张床位的传染病专科 医院并迅速投入使用，陆续新建一批 “方舱医院”, 改扩建一批定点医院, 改造一批综合医院, 向全世界 展现了基建狂魔的中国速度 ${ }^{[10]}$ 。

医疗物资生产供应和医疗支持服务方面, 也积极响 应党和国家号召, 依托完备的工业生产体系, 医疗企 业克服工人返岗不足等困难, 以最快速度恢复医疗用 品生产, 最大限度扩大产能。有条件的企业迅速调整 转产, 有效扩大了疫情防控物资的生产供应, 为疫情 防控提供了重要的物质保障。[11]

\section{4. 思想政治教育途径的拓展探索 ${ }^{[12]}$}

把校园文化建设、网络思想政治教育阵地、思想政 治工作、心理健康教育和社会实践活动、解决大学生 的实际问题等作为拓展的有效途径。

\section{1. 通过学校教育实现思想政治教育的常规 化}

各大中小学校应形成大课程思政理念组织各种线 上学习、线上班会对孩子们进行宣传教育, 指导孩子 积极配合国家疫情防控需要, 科学认识病毒、正确面 对疫情, 鼓励孩子及时有效做好防控、及时反馈需要 解决的问题。

\section{2. 通过家庭教育实现思想政治教育的生活 化}

特殊的防控形势之下，党和国家号召全民居家配 合疫情防控, 众多家庭利用长时间居家相守的机会进 行教育, 通过讲抗疫故事、手工、游戏和观看抗疫实 况等形式对子女进行思想政治教育, 及时答疑解惑适 时帮助调节身心形成生活思政理念。

\section{3. 通过社会教育实现思想政治教育的引导}

党和国家实事求是形成社会思政理念, 通过主流媒
体及时、全面、公开透明地发布疫情信息，并通过各 个栏目向民众传递同心协力共克疫情的信心和决心。

\section{4. 通过网络平台实现思想政治教育的渗透}

微信等手机客户端因它成本低、效率高, 口语化、 碎片化，简单易操作等优势已成为人们的主流应用。 在疫情防控期间，线上交流成为比较符合现实需要的 沟通方式, 所以需要充分探索利用新兴媒体拓展互联 网+思想政治教育的传播途径，培养互联网思维、提 升网络媒介素养，树立网络思政理念，把握互联网及 时性、智能性的特点, 将思想政治教育信息渗透到教 育教学、生活服务过程中，通过网络直播等形式开展 线上线下互动, 在平等、开放、互动、共享氛围中实 现有亲和力的渗透。

\section{5. 思想政治教育方法探索}

此次突发公共卫生事件的处理, 党和国家始终秉 持以人民利益为重, 为保护人民生命安全和身体健康, 倡导人们居家隔离。但是隔离并没有隔离爱, 当我们 看到包括军医在内的很多白衣天使不怕病魔同病患 一起在与病毒作战的大爱, 看到很多工作人员不畏严 寒、不辞辛苦奋战在防控一线, 很多人泪湿双眼。这 正是增强思想政治教育感染力的良好契机、也是发挥 思想政治教育凝心聚力的作用增强亲和力的大好时 机。思想政治教育的方法探索也应坚持 “以人为本”

“不忘初心”的理念，根据不同情况探索更适合的方 法做好做细做精以达成思想政治教育的目标。

由于各个年龄段、各个阶层的知识基础不同、理解 能力各异和时间不统一，所以要对民众进行思想政治 教育, 就需要对不同思想政治教育对象进行分组, 运 用多种手段和方式对思想政治教育工作进行分层，以 人为本，人民至上，把思想政治教育做精，做细，实 施精准教育指导落实到位，提升思想政治教育工作的 实效性和针对性，有利保障战疫胜利的全员拥有饱满 的精神状态、坚定的信念支撑。

\section{1. 实践体验的方法}

在此次疫情防控中, 中国社会上下动员, 积极行 动, 为决战疫情各尽所能, 以各种形式成为抗击疫情 的实践参与者。在抗疫实践参与中，体验有利于思想 道德素质的提高、人格升华、能力提升，体验到了自 律配合、爱国不分年龄不分职业、“万众一心，众志 成城” 等重要的道德认识, 巩固了道德观念, 磨炼了 道德意志。实践参与体验也有利于培养生存意识、提 升生存能力, 增强科技意识、提升科技能力, 增强创 新意识、提升创新能力, 提升适应社会生活的能力、 协调人际关系等。

\section{2. 榜样示范的方法}

疫情防控期间, 涌现出很多平凡的英雄。他们是 
新时代的楷模, 他们以无声的力量在感染激励着抗击 疫情的广大民众, 他们向民众示范了对人对事的态度 和行为表现, 传递的是一种榜样的精神激励, 更是战 胜疫情的信心和决心。他们的示范更容易增强思想政 治教育的可信度，使思想政治教育入脑入心。

\section{3. 心理咨询的方法}

国家及时开展心理干预, 运用心理学的知识和咨 询技巧在尊重、理解、信任的前提下，通过沟通疏导 教育解除心理的问题，引导民众正确面对，便于人们 及时调节心理解除焦虑。心理咨询理论和方法在深入 理解人的心理和行为的实质的基础上为思想政治教 育提供重要的帮助。

\section{4. 自我教育自律的方法}

马克思主义指出: 外因通过内因起作用。思想政 治教育不仅强调外在灌输引导, 而且还注重受教育者 的自我教育主体力量的发挥。公民在正确的自我认识、 自我要求的基础上, 依靠自己的努力, 自我调整、自 我提高, 自觉达到社会要求。此次公共卫生事件的防 控中, 公民表现得高度自律并自觉作出自我牺牲, 使 社会防控部署措施得以全面顺利落实。

\section{6. 结论}

中华民族是在多灾多难中饱经磨砺、团结一致共 克难关中逐步成长壮大的。在克服大灾大难的实践中 积淀了优秀文化传统、优秀民族精神, 都成为今天和 以后思想政治教育重要的养分被吸收传承。思想政治 教育需要根据变化了的时代特点, 不断丰富内容完善 体系, 拓展思想政治教育的功能, 创新思想政治教育 的途径和方法, 以达到在突发公共卫生事件中思想政 治教育的实效。

\section{REFERENCES}

[1] Ma,G.X, Hu,G.J. ( 2018 ) A study on the countermeasures to the unexpected events in colleges and universities -- from the perspective of ideological and Political Education. J. Journal of Huangshan City College 20:89-92.

[2] Guan,X . (2020) Probe into the path of strengthening the life education of college students in the new era. J. Knowledge Economy 9:97,99.

[3] Song,X.C,Liu,H. ( 2017 ) The core of life education: The cultivation of students consciousness of life. J. Journal of Lishui College.39:91-95.

[4] Qin,L.H. (2018) On the effective integration strategy of ideological and Political Education on
Internet and Mental Health Education for college students. J. Journal of Guangxi Institute of Education 157: 137-140.

[5] Rao,W.H. (2006)Mental Health Education is an important part of ideological and political education. J. Journal of Guangxi Young Cadres College. 16(3):16-18.

[6] Xu,M , Kang,D.D . (2014) On the cultural function of ideological and Political Education from the perspective of popularization of Marxism. J. Truth-seeking. 17:83-86.

[7] Zhu,W, Wang,T. (2017) On the cultural function of ideological and Political Education . J. Research on ideological and Political Education. 33:96-99.

[8] Wen,X.P. (2018) Image Narration and Narrative Image: The history and future of the image of ideological and political education. J. Research on ideological and Political Education 34: 106-111.

[9] WangX.F,Kong,Z.X. (2020)Analysis on the path of youth patriotism education under the epidemic situation of new coronary pneumonia. J. Journal of Heilongjiang Institute of Technology (Comprehensive Edition). 20:23-27.

[10] 《China's Fight Against COVID-19》. (2020) https://baijiahao.baidu.com/s?id=166455535272 $7855157 \&$ wfr $=$ spider $\&$ for $=$ pc.

[11] Yang,H.M, Fan,Y.R. (2020)The generative logic of the ideological and political education function of the youth subculture on the Internet . J . Research on ideological education.315:116-121

[12] Liu,H, Guo,F.Z. (2018) On the development of the carrier of ideological and political education in colleges and universities. J. Heilongjiang higher education research.287:128-130.

[13] Chen,Z.Z, Yan,S.Z. (2010) On the characteristics of ideological and political education in Switzerland. J. Research on ideological and Political Education 26:32-35. 